\section{Violência hoje}

\section{Violence today}

Michel Wieviorka ${ }^{1}$

\footnotetext{
1 École de Hautes Études de Sciences Sociales. 54 Boulevard Raspail, 75006, Paris. michel.wieviorka@ehess.fr
}

\begin{abstract}
In this paper, the author seeks to approach contemporary violence in its most different expressions, including the use of the most recent developments in biology, bacteriology, chemistry and nuclear physics. The central idea is that violence changes, and with it the way it is perceived and how we react to it. The text, besides putting violence into a historical context, analyzes 1) the big transformation(s) in the world: the end of the Cold War, the new industrial structure and its consequences for the decline of the labor movement, globalization and the new forms of victimization; 2) in the second part, the author points to new approaches and characterizes novel contemporary subjects.
\end{abstract}

Key words Violence in history, Violence and subjectivity, Violence in our times, Violence and globalization
Resumo Neste artigo o autor busca conceituar a violência contemporânea mostrando as mais diferentes perspectivas com que ela aparece, inclusive o terrorismo e suas novas formas de expressão que utilizam os mais recentes desenvolvimentos da biologia, da bacterologia, da química e da física nuclear. A idéia central é de que a violência muda, mudam suas percepções e os comportamentos em realação a ela. No texto, além de uma contextualização histórica, são analisadas 1) as grandes transformações do mundo: o fim da Guerra Fria, a reestruturação produtiva e suas conseqüências para o declínio do movimento operário e a globalização e as novas formas de vitimização; 2) a seguir são apontadas as novas formas de abordagem e a caracterização de novos sujeitos, consonantes com a contemporaneidade.

Palavras-chave Violência na história, Violência e subjetividade, Violência e comtemporaneidade, Violência e globalização 


\section{Introdução}

Hoje, novas formas da violência surgem ou ameaçam as condutas de risco, por exemplo, a perspectiva de um terrorismo biológico, bacteriológico, químico ou nuclear, atos de martirização, sacrificando-se a vida ao causar a morte de outrem, destruição e autodestruição caminhando juntas, etc.

A violência muda, e a mudança está também nas representações do fenômeno. Se, freqüentes e numerosos esforços são empreendidos no sentido de fornecer uma apresentação objetiva, convertida em cifras, da violência - estatísticas de crimes, de delinqüência, de motins etc. -, esta também não deixa de ser altamente subjetiva, ela é aquilo que em um dado momento uma pessoa, um grupo, uma sociedade considera como tal. Isso nos leva a interessantes debates. Na França, por exemplo, ao longo dos anos 80 e 90 , a questão era: estaria a violência objetivamente aumentando ou estaria aumentando o sentimento de falta de segurança, independentemente dos fatos? As percepções da violência são função de outros elementos que não o fenômeno ele mesmo, em sua aparente objetividade. Por exemplo, a mesma briga entre jovens será percebida como banal e sem gravidade, num bairro onde reina o pleno emprego e os habitantes não têm maiores preocupações com o futuro, e como extremamente preocupante, num bairro onde imperam o desemprego e a desordem.

Não podemos mais abordar a questão da violência hoje como o teríamos feito há apenas vinte ou trinta anos. O mundo transformou-se consideravelmente. Mas será que dispomos de modos de abordagem que permitam lançar um olhar novo ou renovado sobre o fenômeno?

\section{As grandes transformações do mundo}

\section{O fim da Guerra Fria}

Consideremos o planeta tal como ele se apresenta nos anos 50 ou 60 do século 20. Ele é estruturado, no essencial, por um conflito central que opõe as duas superpotências do momento, os Estados Unidos e a União Soviética. Desde os acordos de Yalta, assinados no momento em que a Segunda Guerra Mundial não havia terminado totalmente, o mundo é dividido em função de suas duas zonas de influência. E a Guerra Fria constitui a partir de então um enfrentamento maior, mas que não conduz a uma guerra frontal, nem mesmo a efetivas oposições bélicas mais localizadas. A guerra da Coréia e depois a do Vietnã não geram o enfrentamento direto das duas superpotências e não levam a uma guerra mundial generalizada, elas permanecerão localizadas. Entre os dois blocos, as armas nucleares asseguram uma certa prudência, exercem um efeito dissuasivo; a perspectiva de seu uso evita a passagem a extremos, apesar dos momentos de forte tensão, especialmente por ocasião dos mísseis de Cuba. A violência bélica vê-se, assim, limitada, no mundo todo, pois cada país está na órbita mais ou menos clara de uma das superpotências, e é sabido que uma guerra localizada corre o risco de acarretar um conflito mundial.

Relatório do Human Security Centre de Vancouver, publicado em outubro de 2005, lembra que durante a Guerra Fria houve muitas guerras por procuração no Terceiro Mundo, violências locais por vezes altamente destruidoras. Não se deve, portanto, ter uma imagem excessivamente idílica desse período. Mas a Guerra Fria evitou a generalização ou a extensão da guerra. Exerceu, ainda, um efeito de controle sobre o terrorismo internacional, conduzido sobretudo por atores que invocam a causa palestina e que nunca foram tão longe quanto no período atual.

Dito em uma frase: ao término da Guerra Fria (uma data cômoda, aqui, é a da queda do muro de Berlim, em 1989), o mundo fica órfão de um princípio de estruturação conflitual que evitou, muito mais do que autorizou ou facilitou, a violência militar.

Em seguida, surgiram novas linhas de fratura, as guerras civis revestiram-se de um aspecto completamente diferente, instalaram-se fenômenos maciços de violência nova ou renovada. Foi assim que o terrorismo se tornou "global" - noção à qual retornaremos -, a criminalidade organizada prosperou, aí também ligada à globalização. E se, segundo o relatório do Human Security Centre, o número de conflitos armados clássicos entre os Estados por certo diminuiu 40\% desde 1992, e se o número de conflitos mais violentos (aqueles que causam mais de 1.000 mortes por ano no campo de batalha) está em queda de $80 \%$; se os golpes de Estado ou as tentativas de golpe de Estado diminuíram - dez tentativas em 2004, enquanto em 1963 houve vinte e cinco -, por outro lado, outras formas de violência se desenvolveram. O terrorismo "global" atacou diversas vezes, causando freqüentemente muitas dezenas de vítimas por atentado e, por outro lado, de modo geral, a porcentagem de vítimas civis em relação às vítimas militares aumentou de forma 
considerável. A barbárie instaurou-se em todos os tipos de lugar do mundo, inclusive na Europa, onde se podia considerar que, depois do nazismo, não mais se veriam crimes de massa de tipo genocida: o desmembramento da antiga Iugoslávia passou pelas violências da "purificação étnica" enquanto esse país, na época da Guerra Fria, havia antes constituído um elemento de estabilidade internacional. O genocídio dos Grandes Lagos causou mais de um milhão de mortes. E, hoje, a guerra do Iraque se prolonga por meio de violências cotidianas extremamente sanguinárias e que poderiam prefigurar uma guerra civil.

O fim da Guerra Fria evidentemente não explica tudo, e uma análise mais fina, em matéria geopolítica, também deveria levar especialmente em conta o fim do colonialismo, os processos de descolonização, o fim da dependência para muitas sociedades da América Latina. Entretanto, podese pensar que desempenhou um papel importante. Os atos violentos da Guerra Fria, em particular nas guerras ditas "por procuração" (proxy war), deviam ter terminado ali. Seu término, graças a intervenção da ONU (mas também de outros atores, especialmente de ONGs) em operações de prevenção ou manutenção da paz, dá origem a novas mediações, negociações, interposições e, assim, autoriza a aprendizagem da gestão negociada, democrática, dos conflitos.

Mas, ao contrário, enquanto a Guerra Fria restringia o crime organizado em um certo nível e exercia pressão sobre o terrorismo internacional, uma vez que os principais atores dessa violência precisavam de Estados "patrocinadores", eles mesmos, com freqüência, na órbita da União Soviética, seu fim abre caminho para expressões mais maciças do crime organizado e para formas agudíssimas de terrorismo.

O fim da Guerra Fria, portanto, não inaugura por si mesmo um novo período de violências militares ou terroristas, mas, antes, transforma suas violências. Significa, para falar como o historiador Charles Tilly, a invenção de um novo repetório de ação, o que também aparece ao se considerar a questão das armas nucleares. No passado, como já mencionado, as armas nucleares constituíam um fator de moderação e mesmo de paz. Hoje, tornaram-se um fator ou, pelo menos, um símbolo de riscos importantes, associado às imagens de desestabilização ou de crise regional, em especial no Oriente Médio e na Ásia, assim como a problemas novos de disseminação.

\section{O que o declínio do movimento} operário nos ensina

Ao analisar uma questão muito específica, abordaremos uma idéia muito geral. Na Europa, mas também em outras partes do mundo, a indústria, inicialmente, constituía o cerne da vida coletiva, e as relações sociais que ela moldava assumiram o aspecto de um conflito social estrutural, opondo o movimento operário aos senhores do trabalho. A noção de "sociedade industrial" não pode ser aplicada de maneira uniforme a todos os países, sobretudo porque para alguns essa questão não diz respeito ou o diz muito pouco. Mas para aqueles que conheceram essa experiência, um ponto essencial merece ser notado: eles saíram da era industrial clássica, dominada pela existência de fortes concentrações de operários e por modos de organização científica do trabalho que implicam numerosos postos de trabalho não qualificados. Ora, a história do movimento operário, em toda parte onde ela foi longa e importante, apresenta uma característica principal: quando esse movimento é forte, quer repouse sobre uma forte capacidade de mobilização, quer se organize em sindicatos e outras formas de organização operária capazes de negociar, capazes também, como em todas as variantes da socialdemocracia, de se prolongar sem vínculos de subordianação a um partido político, então, o espaço da violência operária é reduzido, ou mesmo nulo. Por outro lado, em período de nascimento do movimento operário, quando ele não está organizado, quando os sindicatos não se encarregam dos problemas da situação ou da condição proletária, e em período de declínio histórico, quando ele perde sua centralidade e sua capacidade de ação, constata-se que o espaço da violência, inclusive terrorista, aumenta, e que atores vêm como que substituir o movimento ausente e falam em seu nome de forma violenta.

Essa constatação, que em meu livro Sociétés et terrorisme ${ }^{1}$ estabeleci em especial para diversas fases do terrorismo anarquista ou de extrema esquerda na Europa, merece ser alargada e reformulada, sob a forma de uma hipótese sociológica geral: o fato de o espaço social não ser estruturado por um conflito que produza as modalidades de tratamento das demandas dos atores faz com que a violência encontre mais lugar para se exprimir. Em situações diferentes daquelas que remetem ao nascimento ou ao declínio do movimento operário, é de fato possível mostrar que a violência vem substituir um conflito, ou seja, uma relação conflitual não-encontrável ou perdida.

Cumpre mesmo dar um passo a mais e esten- 
der essa observação: a violência é o contrário do conflito institucionalizável, ela traduz a existência de problemas sociais que não são transformados em debates e em conflitos de sociedade.

\section{A globalização}

A noção de globalização começou a se impor a partir dos anos 70 e, sobretudo, nos anos que se seguiram ao fim da Guerra fria. Ela foi com freqüência muito ideológica, termo que corresponde então à idéia de que o neoliberalismo é a única e a melhor forma de que se pode revestir a economia num mundo marcado, como dizia Francis Fukuyama com inacreditável arrogância, pelo fim da História e pelo triunfo dos mercados e da democracia. Essa noção foi não raro criticada, e parece ter sido como que ultrapassada depois do 11 de Setembro de 2001, quando o mundo pareceu ser de súbito dominado não mais, ou não mais apenas, pelas forças do dinheiro, o capitalismo sem fronteiras, os mercados, os fluxos financeiros e comerciais, mas pelo terrorismo e pelas respostas bélicas ao terrorismo. Ela também foi criticada por aqueles que, como Samuel Huntington, insistiram nas dimensões culturais, civilizacionais dos grandes conflitos do mundo, pela idéia da entrada na era do "choque das civilizações". Enfim, ela também alimentou debates sobre suas conseqüências políticas e sociais, a começar, como disseram diversos especialistas dos anos 80 e 90, pelo enfraquecimento dos Estados-nações - tese em relação à qual em grande parte se voltou atrás, a ponto de certos trabalhos, como os de Jean-François Bayart, insistirem, ao contrário, na idéia de um vínculo direto entre globalização e formação ou fortalecimento dos Estados-nações.

Passemos agora ao essencial de nossas preocupações: a globalização permanece uma noção útil caso se trate de pensar tipos de fenômeno, culturais, sociais, políticos, e não apenas econômicos, e em função da combinação que aí se dá entre dimensões mundiais, trans- ou supranacionais, e dimensões nacionais ou locais. É assim que o terrorismo se torna "global", isto é, que ele conjuga aspectos planetários, metapolíticos, religiosos, em especial com o islamismo radical, e raízes no seio das sociedades por ele afetadas. Os atentados de 11 de setembro de 2001 são aqui ao mesmo tempo fundadores - ainda que na verdade se possam assinalar atentados que deles dão indícios ou os anunciam ao longo de todos os anos 90 - e excepcionais: são os únicos, com efeito, empreendidos por atores vindos de fora da sociedade visada, os Estados Unidos. Em outros lugares, os terroristas subordinam-se a uma articulação, por certo variável de uma experiência a outra, a lógicas gerais, mundiais, e a lógicas locais.

Por exemplo, os autores dos atentados de Londres, em julho de 2005, guiavam-se por uma lógica religiosa e geopolítica mundial, mas, ao mesmo tempo, estavam ligados à sociedade inglesa, e ainda, por sua ação, davam mostras de um vivo ressentimento quanto às suas condições locais de existência. Poderíamos fazer observações bastante semelhantes no que diz respeito ao crime organizado, ligado às drogas, por exemplo, que opera segundo lógicas planetárias, transnacionais, mas cujo funcionamento é melhor compreendido caso se considerem as raízes dos atores em tal ou qual país.

Um outro aspecto da globalização que intervém na violência contemporânea é o que o geógrafo americano David Harvey melhor formulou, ao dizer que ela corresponde à dupla compressão do tempo e do espaço. Hoje a informação, em parte, circula no mundo inteiro a velocidade instantânea e, em parte, é facilmente guardada na memória e acessível com não menos facilidade. Uma declaração política, uma medida jurídica tomada em Brasília, pode ser conhecida no mesmo instante no outro lado do mundo; e ela também pode ser invocada dez anos depois por quem quer que seja, mais uma vez em toda parte do mundo. O que faz com que os discursos de ódio possam circular apesar das proibições morais ou jurídicas e alimentar campanhas que podem assumir um aspecto violento. Acabamos de vê-lo com o caso das "caricaturas" do Islã, quando charges publicadas num jornal dinamarquês foram retomadas, alguns meses mais tarde, em diversos países muçulmanos, suscitando, numa velocidade incrível, mobilizações antidinamarquesas, antiocidentais ou hostis a tais ou quais países que possam por vezes ter tomado atitudes de ataque contra bens ou símbolos. Assim também, nada se compreende do anti-semitismo contemporâneo sem levar em conta seu caráter "global", e a circulação do discurso e das imagens do ódio aos judeus no mundo inteiro, via internet ou por meio das parábolas de televisão.

\section{A era das vítimas}

A última característica nova do mundo contemporâneo que evocaremos é o avanço, desde os anos 60, de identidades particulares de toda sorte que exigem reconhecimento e, por vezes, reparação pelos crimes de que seus ancestrais 
foram vítimas e que, ao mesmo tempo, se apresentam eventualmente no espaço público a propósito das violências de que hoje mesmo são vítimas. É o que se dá, em particular, com movimentos de caráter cultural, religioso ou étnico, ou nacional, movimentos negros, indígenas, movimentos de descendentes de sobreviventes de um genocídio, por exemplo judaico ou armênio, movimentos ainda de pais ou filhos de vítimas de um poder ditatorial ou totalitário. Esses atores podem ser eles mesmo violentos, por exemplo numa fase de "despertar" (réveil) - foi o caso do terrorismo armênio dos anos 70. Sobretudo, eles atraem a atenção para as conseqüências da violência: esta última é negação ou atentado contra a integridade física e moral de uma pessoa, com efeitos que são vistos eventualmente nas gerações seguintes, ela torna difícil construir-se como sujeito de uma existência coletiva e, com freqüência, também pessoal.

Assim também, desde os anos 60, em muitos países, mobilizações chamaram a atenção para as violências sofridas por mulheres, crianças, deficientes e idosos e, também nesse caso, permitiram que se compreendessem melhor os danos causados pela violência.

Isso leva a uma tendência geral, que vai bem além de tal ou qual país, de tal ou qual experiência, e que faz com que a violência seja cada vez mais considerada aquilo que afeta existências singulares, pessoais ou coletivas, e não apenas, como com freqüência ocorre, aquilo que põe em questão a ordem social ou política, o Estado que se supõe dela deter o monopólio legítimo.

\section{Novos modos de abordagem}

Centremo-nos agora nas ferramentas analíticas que podem permitir abordar a violência.

\section{Os modos clássicos de abordagem}

Há muito tempo as ciências humanas e sociais propõem três modos principais de abordagem da violência. $\mathrm{O}$ mais clássico é aquele que insiste na idéia de que a violência é uma conduta de crise, uma resposta a mudanças na situação do ator ou dos atores, que reage $(\mathrm{m})$ principalmente pela frustração. Essa abordagem encontra suas cartas de nobreza em Alexis de Tocqueville, que explica, a propósito da Revolução Francesa, que a violência foi clara sobretudo ali onde a população havia visto sua posição melhorar: dir-se-ia, escreve ele em L'Ancien Régime et la Révolution², que uma vez que a posição dos franceses melhorava, eles a consideraram ainda mais insuportável. Mas foram sobretudo pesquisadores funcionalistas ou neofuncionalistas anglo-saxões que asseguraram a expansão dessa tese, sob a forma da teoria dita da frustração relativa, nos anos 60 e 70. A idéia de James Davies, por exemplo, retomada muito largamente por Ted Robert Gurr³ , é na verdade aquela em que a violência encontra seu caminho quando a distância entre as expectativas de um grupo e as possibilidades de satisfazê-las se tornam consideráveis e insuportáveis. Esse tipo de abordagem pôde por vezes produzir resultados interessantes. Mas, nos anos 70, muitos trabalhos mostraram suas carências e a grande limitação de seu caráter explicativo. Daí a razão de duas outras linhas de abordagem terem sido amplamente aceitas.

Um segundo tipo de análise, precisamente o mais longe possível das teses à moda de Gurr ou de Davies, insiste no caráter racional e instrumental da violência, inclusive em suas dimensões coletivas - motins, revolução, por exemplo. Esse tipo pode encontrar suas cartas de nobreza em Thomas Hobbes e foi consideravelmete desenvolvido a partir dos anos 60, apoiando-se em especial nos trabalhos do historiador Charles Tilly. Para os defensores da tese dita da "mobilização dos recursos", que recorrem a esse autor, e a outros, como Anthony Oberschall, a violência é uma conduta que nada mais é que um recurso mobilizado por atores como um meio para atingir seus fins. Na maior parte do tempo, essa idéia serve para explicar como atores excluídos do campo político utilizam a violência para aí penetrar e se manter. Uma tal idéia apresenta a vantagem de não mais reduzir a violência à imagem de uma conduta de crise, reativa; ela faz do ator violento um personagem consciente do que está em jogo em sua ação, a qual, ela mesma, faz sentido. Ela defende que, na análise, não se separe a violência do conflito mais geral no qual ela eventualmente surge, greve operária, manifestação camponesa, por exemplo. Ela apresenta uma força explicativa não negligenciável, tanto que com freqüência a violência é instrumental. Mas passa ao largo do que, para nós, é o núcleo duro da violência, que ela reduz a ser um recurso, entre outros, o dinheiro, as redes de solidariedade, por exemplo. Ela nada nos diz daquilo que a violência constantemente apresenta como excesso ou como falta - voltaremos a isso.

Por fim, uma última linha clássica de abordagem, na verdade extremamente grande, postula um vínculo entre cultura e violência. Certos 
autores fazem da cultura, ou antes da civilização, o contrário da violência, como Norbert Elias em seu famoso trabalho sobre o processo civilizatório, no qual ele explica que a modernidade se instalou ao mesmo tempo em que os indivíduos, por exemplo na Court Etiquette, aprendiam a dominar sua agressividade ou seus impulsos violentos. Outros insistem nos vínculos entre certas culturas e a violência, eventualmente por intermédio da socialização e da educação - em referência, por exemplo, ao célebre estudo de Theodor Adorno 4 sobre o anti-semitismo. Um problema com a idéia de um vínculo entre cultura e violência é que a análise deixa de lado todas as mediações políticas e sociais, mas também a espessura histórica que pode separar o momento em que se forja uma personalidade e aquele em que ela passa ao ato.

As abordagens clássicas da violência não podem ser esquecidas ou postas de lado, elas não raro trazem uma luz útil para compreender uma experiência concreta de violência. Mas com muita freqüência não satisfazem o pesquisador, de tanto que passam ao largo de dimensões todavia essenciais, que só podem verdadeiramente começar a ser abordadas introduzindo-se uma noção que em geral não é do âmbito do estudo da violência, a noção de Sujeito.

\section{O sujeito e a violência}

Pode haver na violência aspectos que sugerem uma lógica de perda de sentido: o ator, então, vem exprimir um sentido perdido, pervertido ou impossível, ele é violento, por exemplo, porque não pode construir a ação conflitual que lhe permitiria fazer valer suas demandas sociais ou suas expectativas em matéria cultural ou política, porque não existe tratamento político para essas demandas ou expectativas.

Em outros casos, contudo, não se observa apenas uma falta ou perda de sentido, mas uma sobrecarga, uma pletora. Em certas experiências, a violência se apóia em uma ideologia, dela procede e aí encontra um sentido de substituição. O terrorismo de extrema esquerda conduzido em nome da classe operária na Itália, nos anos 70 e 80, por exemplo, baseava-se numa ideologia na qual os terroristas se arrogavam de maneira artificial a missão histórica de um proletariado, ele mesmo, na realidade, muito distante de acreditar em qualquer papel histórico para si. Por vezes, também, é um mito que está em jogo, uma construção discursiva que permite construir a imagem de uma integração possível de elementos de sentido que de fato se tornam cada vez mais contraditórios: a violência, aqui, se desenvolve quando o mito se desfaz, não se sustenta mais. Mas, principalmente, a religião com freqüência vem conferir um sentido a uma ação violenta, que transcende, então, a política, com o risco de se reinstalar rapidamente em seu nível.

Muitos outros elementos fazem com que a violência seja um fenômeno que as abordagens clássicas não explicam bem. É assim quando ocorrem a crueldade, a violência gratuita, a violência pela violência. Quando o ator não apenas destrói o outro, mas também se autodestrói. Ou ainda quando ele parece não conferir nenhum sentido a sua ação, apresentando-se como irresponsável, tendo agido apenas por obediência a uma autoridade legítima - uma linha de defesa que foi por exemplo a de Eichmann, em Jérusalem, tal como a descreveu Hannah Arendt ${ }^{5}$ em Eichmann à Jérusalem. Rapport sur la banalité du mal.

Diante desses diversos aspectos, a introdução da noção de Sujeito pode trazer uma luz particularmente decisiva. É assim que, a partir de uma definição geral do Sujeito - a capacidade de cada ser humano de se construir, de dominar sua experiência, de produzir suas escolhas -, fui levado a propor a distinção de cinco casos de figura, que correspondem cada um a um tipo de subjetividade que se pode ligar à violência em meu livro La violence ${ }^{6}$.

- Sujeito flutuante é aquele que, não chegando a se tornar ator, passa à violência: por exemplo, o jovem imigrado de um bairro à deriva que queima os carros, por não poder exprimir de outro modo suas demandas, seu desejo de construir sua existência.

- Hipersujeito é aquele que compensa a perda de sentido (caso precedente) pela sobrecarga, o excesso, dando-lhe um sentido novo, ideológico, mítico, religioso por exemplo.

- Não-sujeito é aquele que age de maneira violenta, sem comprometer de maneira nenhuma sua subjetividade, contentando-se em obedecer, como nas célebres experiências de Stanley Milgram7.

- Anti-Sujeito é essa face do Sujeito que não reconhece a outrem o direito de ser Sujeito, e que só pode se construir na negação da humanidade do outro.

- Sujeito em sobrevivência, enfim, remete a essa virtualidade que faz com que, sem considerar toda agressividade, possa acontecer de um indivíduo se sentir ameaçado, em sua existência mesma, e conduzir-se de maneira violenta para assegurar sua sobrevivência.

Essa tipologia, apresentada aqui de maneira 
muito sucinta, por certo mereceria ser especificada, e o vocabulário que utilizo talvez não seja o mais adaptado - mas é preciso dizer que até aqui não dispúnhamos de categorias que permitissem dar conta desses diferentes casos de indivíduos. Ela apresenta a vantagem de nos ajudar a abordar o que há de mais misterioso, e de mais central, na violência: não as frustrações que ela eventualmente revela, não os cálculos mais ou menos racionais daquele que a ela recorre em caso de necessidade, tampouco a cultura de onde ele veio. Mas as lógicas de perda e sobrecarga de sentido, no curso das quais ocorre de a violência se construir, a parte de excesso e de falta que ela comporta, a subjetividade torcida, por vezes também pervertida ou perversa, que a torna possível.

\section{Referências}

1. Wievioka M. Sociétés et terrorisme. Paris: Fayard, 1988.

2. Tocqueville A. L'Ancien Régime et la Révolution. Paris: Gallimard, 1967.

3. Gurr, RT. Handbook of Political Conflict. New York: The Free Press, 1980.

4. Adorno T. The authoritarian personality. New York: Harper, 1960.

5. Arendt H. Eichmann à Jérusalem. Rapport sur la banalité du mal. Paris: Gallimard, 1966.

6. Wieviorka M. La violence. Paris: Hachette-Littératures, 2005. (Coll. Pluriel).

7. Milgram S. Soumission à l'autorité. Paris: Calmann-Lévy, 1974. 